\title{
Method to Realize the Tilt Monitoring and Instability Prediction of Hazardous Rock on Slopes
}

\author{
Zheng He $\mathbb{D}^{1},{ }^{1,2}$ Mowen Xie $\mathbb{D}^{1},{ }^{1}$ Zhengjun Huang $\mathbb{D}^{1},{ }^{1}$ Guang Lu, ${ }^{1}$ Bo Yan, ${ }^{2}$ and Jianfei Wang ${ }^{3}$ \\ ${ }^{1}$ School of Civil and Resources Engineering, University of Science and Technology Beijing, Beijing 100083, China \\ ${ }^{2}$ Beijing Zhongguancun Institute of Safety Science Co., Ltd., Beijing 102199, China \\ ${ }^{3}$ Yunnan Construction and Investment Holding Group Co., Yunnan, Kunming 650000, China \\ Correspondence should be addressed to Mowen Xie; mowenxie@126.com and Zhengjun Huang; huang_jun.0518@163.com
}

Received 4 March 2021; Accepted 28 May 2021; Published 4 June 2021

Academic Editor: Xun Xi

Copyright (C) 2021 Zheng He et al. This is an open access article distributed under the Creative Commons Attribution License, which permits unrestricted use, distribution, and reproduction in any medium, provided the original work is properly cited.

Hazardous rock refers to an unstable rock block that is cut by weak structural planes and gradually separates from the slope. Hazardous rock generally collapses rapidly, and at present, it is challenging to effectively identify the separation degree of the rock and accurately predict its sudden failure. In this study, focusing on a hazardous rock with tilt behavior, a microelectromechanical system (MEMS) acceleration sensor is used in combination with the calculation principle of the included angle of the space vector to establish a microtilt angle monitoring method. A physical model test is designed, in which a thermally sensitive material (with heat-sensitive strength) is adopted as the weak structural plane of the hazardous block, and the change in the tilt angle during the process of block instability is monitored at a sampling frequency of $1000 \mathrm{~Hz}$. The test results show that the accelerated evolution of the tilt angle is a precursor to hazardous rock failure. In the rapid acceleration stage, the reciprocal of the tilt angle rate is approximately linear with time, and a correlation equation is obtained. Assuming that the change rate of the tilt angle is approximately infinite, the failure time of hazardous rock can be predicted using the correlation equation. In addition, the effectiveness of the instability prediction method based on microtilt angle monitoring is verified by analyzing the long-term monitoring data of hazardous rock.

\section{Introduction}

Hazardous rock refers to an unstable rock block that is cut by multiple sets of structural planes on a steep rock slope and gradually separates from the slope under the action of gravity, weathering agents, seepage pressure, and seismic force. The failure mode of hazardous rock involves sliding, toppling, and falling separation forms (Figure 1) [1]. Notably, the collapse of hazardous rock is a global mountain geological disaster that considerably threatens the safety of infrastructure, human life, and property. To reduce the disaster risks and losses, it is necessary to effectively prevent hazardous rock collapse events.

To date, strength theory has generally been used to identify the stable state of hazardous rock at a certain instance [2-4]. When the tensile (or shear) stress on the control fissure of the hazardous rock exceeds the tensile (or shear) strength, the rock mass is expected to collapse [5]. However, conducting regular and detailed investigations of the geological characteristics, structural features, and mechanical properties of hazardous rocks is highly labor and cost intensive. Therefore, the application of mechanical analysis or numerical simulation methods to the long-term monitoring of hazardous rock instabilities is challenging. In addition, although the mechanical reinforcement of key engineering rock slopes through supporting measures is an effective prevention and control method $[6,7]$, certain limitations remain in the context of geological disaster applications. For example, more than 300,000 hidden danger points pertaining to geological disasters exist in China, and hazardous rocks account for nearly $20 \%$ of these points. Due to the complex installation procedure and high cost of the reinforcement method, this approach is not suitable to realize widespread installation under hazardous rock 


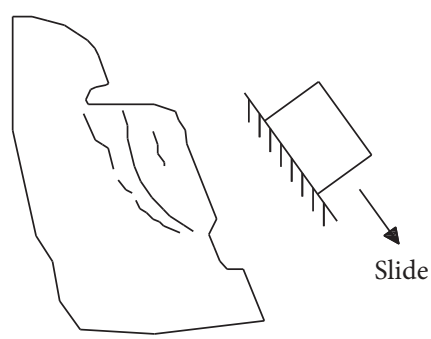

(a)

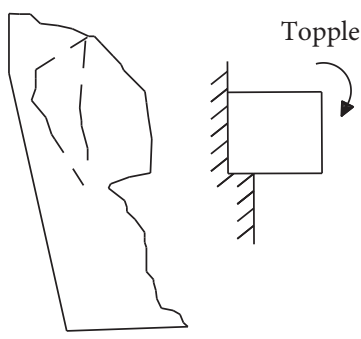

(b)

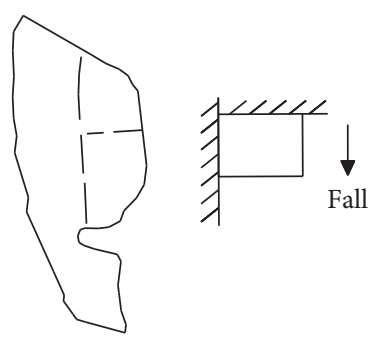

(c)

FIgURE 1: Failure mode of hazardous rock: (a) sliding; (b) toppling; (c) falling.

conditions. In summary, on-site monitoring is often the most suitable technique to prevent hazardous rock disasters.

For large-scale rock slopes, synthetic aperture and laser radars have been used to regularly monitor rock displacement [8-11]. In the case of small-scale hazardous rock, sudden instability and destruction may occur even under a small amount of separation, and thus, monitoring must be realized with a high-resolution and at a high-sampling frequency. The early warning that can be obtained using the manual monitoring method through a total station is not adequately timely. In addition, the method to monitor a crack opening through an extensometer involves the disadvantages of low applicability and complicated installation and maintenance [12]. The abovementioned method identifies the separation of hazardous rock by monitoring the displacement; however, for hazardous rock masses with tilt behavior (Figure 1(b)), the tilt angle of the rock is the main separation feature. Therefore, the development of a monitoring and early warning system that can monitor the microtilt angle of rock masses in real-time and analyze the tilt monitoring data to accurately predict the failure time of hazardous rocks is of significance to guide the risk management of rock collapse disasters.

In recent years, with the development of microelectronics technology, researchers have formulated a new monitoring method that adopts the microelectromechanical system (MEMS) technology to estimate the risk of slope failure by monitoring the slope surface tilt angle [13-16]. Compared with the traditional instruments used to monitor slopes, MEMS sensors are small and low cost, and thus, the cost of building an early warning system can be considerably reduced. Considering this aspect, the author previously developed a high-resolution, low-cost, and low-power tilt sensor by using MEMS technology [17]. A MEMS tiltmeter is fixed onto the surface of the hazardous rock body to realize high-frequency tilt angle acquisition. Additionally, a solar power supply system is used to ensure self-powered characteristics, and the data are transmitted through wireless network timing or threshold triggering, thereby ensuring the real-time and long-term collection of the sensor data.

Research on the slope failure time prediction can be traced back to the middle of the 20th century. Saito [18] conducted a series of triaxial compression tests and noted that the logarithm of the slope failure time was proportional to the logarithm of the strain rate. Fukuzono [19-21] conducted a physical test of slope loading failure and observed that the logarithm of the acceleration of the slope was proportional to the logarithm of the velocity; moreover, the correlation equation of the inverse velocity and time could be used to estimate the slope failure time. Due to the clarity of the parameters in this equation, the associated approach has been widely used to predict the failure time of a slope [22-28], and its general form can be expressed as follows:

$$
\frac{1}{V}=\left[A(\alpha-1)\left(t_{f}-t\right)\right]^{[1 /(\alpha-1)]}
$$

where $V$ and $t$ denote the time and deformation rate of the acceleration stage, respectively; $A$ and $\alpha$ are the fitting parameters; and $t_{f}$ is the failure time of the slope. The equation shows that the curve defined by each point of $t$ and $1 / v$ is linear, convex, and concave if $\alpha=2, \alpha>2$, and $1<\alpha<2$, respectively. When $\alpha=2$, the failure time of a slope can be predicted from the time $\left(t_{f}\right)$ when $(1 / v)$ equals 0 (infinite velocity). Voight $[29,30]$ suggested that equation (1) can be interpreted as a general material failure law governing the accelerated creep. According to experimental test results, $\alpha$ generally ranges $1.5-2.2$ [19-21]. Specifically, for approximately $50 \%$ of these measurements, $\alpha$ is close to 2 [28]. Moreover, practical experience has demonstrated that the inverse velocity curve is usually nearly linear, especially in the final stage of slope failure [31-35].

In this study, a MEMS acceleration sensor is used in combination with the calculation principle of the space vector included angle to establish a microtilt angle monitoring method. A physical model test is designed, in which a thermally sensitive material (with heat-sensitive strength) is used as the weak structural plane of the rock mass, and the change in the tilt angle during the process of rock block instability is monitored at a sampling frequency of $1000 \mathrm{~Hz}$. The results show that the accelerated evolution of the tilt angle is a precursor to hazardous rock failure. The correlation equation between the tilt angle rate and time in the rapid acceleration stage is obtained, and a method to predict the rock failure time is formulated. In addition, the effectiveness of the instability prediction method based on microtilt angle monitoring is verified by analyzing the longterm monitoring data of hazardous rock. 


\section{Monitoring Method}

2.1. Tilt Angle Algorithm. To acquire the tilt angle data of the instability evolution process of hazardous rock in real-time and at high frequency, we developed a tiltmeter by using a MEMS acceleration sensor. In particular, by determining the component changes in the gravitational acceleration on the three-way sensitive axis of the sensor, combined with the calculation principle of the included angle of the space vector, the tilt angle can be recorded at a sampling frequency of $1000 \mathrm{~Hz}$. Figure 2 shows a schematic of the component change in the gravitational acceleration on the sensor's sensitive axis.

If the gravitational acceleration component vector (hereinafter referred to as the acceleration vector) in the initial coordinate system is $\overrightarrow{O G}_{1}$,

$$
\overrightarrow{\mathrm{OG}}_{1}=\left(\mathrm{ax}_{1}, \mathrm{ay}_{1}, \mathrm{az}_{1}\right) \text {. }
$$

If the acceleration vector in the rotating coordinate system is $\overrightarrow{O G}_{2}$,

$$
\overrightarrow{\mathrm{OG}}_{2}=\left(\mathrm{ax}_{2}, \mathrm{ay}_{2}, \mathrm{az}_{2}\right)
$$

Using the included angle of the space vector to represent the tilt angle $\theta$ ( $\mathrm{rad}$ ) measured using the sensor yields

$$
\theta=\arccos \left(\frac{\overrightarrow{O G}_{1} \cdot \overrightarrow{O G}_{2}}{\left|\overrightarrow{O G}_{1}\right| \cdot\left|\overrightarrow{O G}_{2}\right|}\right)
$$

The advantages of this angle monitoring method include a high sampling frequency $(0-1 \mathrm{kHz})$ and applicability to sudden collapse disasters; moreover, no specific installation direction must be ensured for the sensor, which can simplify the installation process for technicians under complex terrain conditions.

2.2. Field Monitoring System. The complete monitoring system of a slope rock mass includes data collection, transmission, reception, analysis, judgment, warning, and response aspects. The perceptual layer of the hazardous rock monitoring system adopts the MEMS tiltmeter to collect the tilt information of the rock mass. In addition, the wireless communication method using long-range radio (LoRa) technology transmits data to the base station over a long distance with low power consumption. Subsequently, the 2G/4G/5G wireless module transmits the measurement data to the server computer for further storage and processing. The application layer is based on the comprehensive analysis of the multisource information of the rock mass and provides an accurate prediction and a rapid alarm regarding the slope rock mass condition. The system framework is shown in Figure 3.

\section{Laboratory Test}

3.1. Test Model. A concrete block is used to represent unstable rock. The weak structural plane is constructed using a material with heat-sensitive strength; specifically, sand and gypsum are used as the aggregates, and paraffin is used as the gelling agent [5]. An electric heating element is embedded in the material to control the strength to the weak structural plane. The heat-sensitive material is used to bond the concrete block and based part. As the heating element heats up, the strength of the material of the weak structural plane gradually deteriorates. Simultaneously, the MEMS tiltmeter is used to record the tilt angle of the concrete block at a sampling frequency of $1000 \mathrm{~Hz}$. Figure 4 shows a schematic of the test model. Table 1 presents the material parameters of the different test groups.

3.2. Test Procedures. Heating modes with different temperature gradients are set for each of the two specimens to establish four test groups, as shown in Figure 5. As heat transfer progresses between the electric heating element and weak structural plane, the stability of the concrete block continually decreases, and the block ultimately collapses. The infrared thermal image of the concrete block is shown in Figure 6. The whole process of the tilt angle change during block instability is recorded in the test.

3.3. Test Advantages. The essential cause of collapse of hazardous rock is the strength degradation of the weak structural [5]. In the conducted test, the concrete material ensures that the block has sufficient weight. The strengthsensitive material of the potential failure plane guarantees its own strength and ensures that the block is closely connected with the base part; moreover, this material exhibits similarities with soft rock in terms of the rheological mechanical properties [36]. The advantages of this experiment are as follows: (1) the whole process of rock collapse under gravity can be simulated; (2) the sample frequency of $1000 \mathrm{~Hz}$ ensures the real-time acquisition of the block dip angle; and (3) the experiment exhibits a high operability and repeatability.

3.4. Test Results. Figures 7-10 show the time history of the tilt angle of the 4 groups of model tests calculated using equation (4) with average smoothing. Due to the difference in the volume, weight, strength of the weak structural plane, and strength reduction rate of the block, the blocks collapses when the tilt angle increases to $2.8^{\circ}, 8.7^{\circ}, 18.8^{\circ}$, and $17.3^{\circ}$. The four sets of monitoring curves exhibit clear evolutionary characteristics; that is, the tilt angle accelerates rapidly before block instability. In addition, at the beginning of the acceleration phase, the changes in the tilt angle in the four groups of tests lie within an extremely small range $\left(<3^{\circ}\right)$, and the proposed monitoring method can realize the real-time and high-resolution acquisition of the microtilt angle.

\section{Field Monitoring}

4.1. Description of the Monitoring Site. The field monitoring location of the hazardous rock is in Hubei Province, China, with a subtropical monsoon climate. The multiyear average temperature in the region is $15.4^{\circ} \mathrm{C}$, the rainfall is mostly 


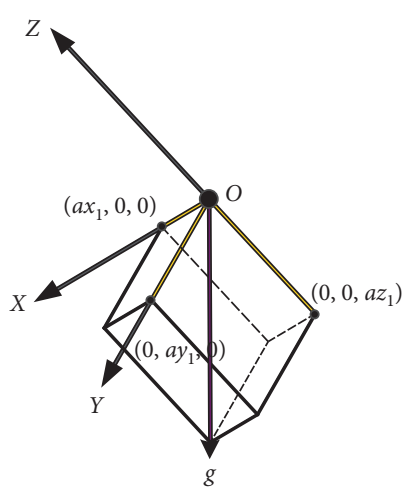

(a)

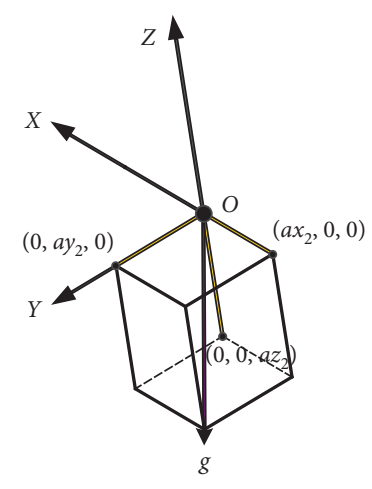

(b)

FIGURE 2: Coordinate change in the gravity acceleration in the (a) initial and (b) coordinate systems.

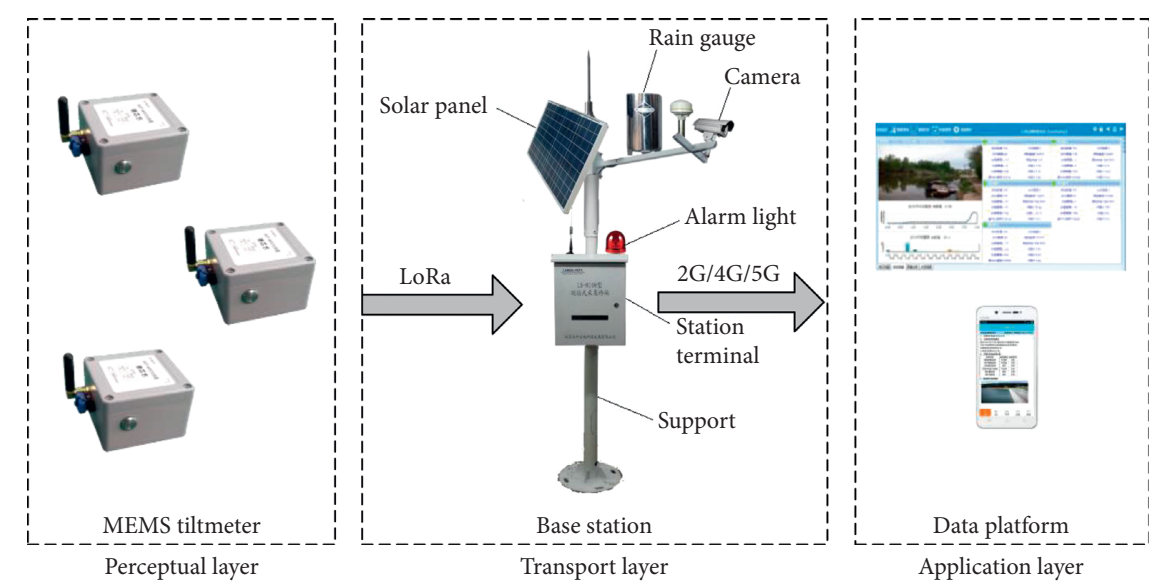

FIGURE 3: Internet of things framework of the monitoring system.

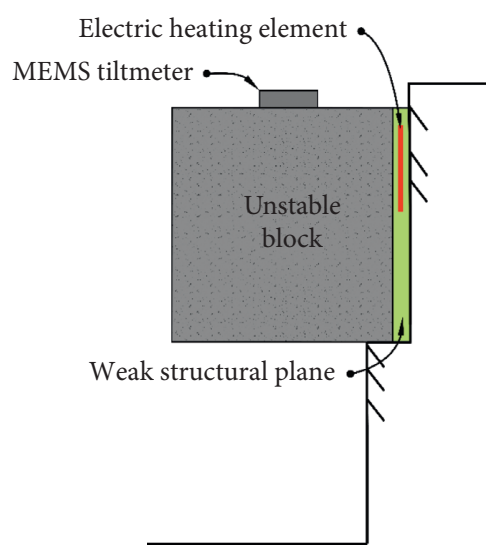

(a)
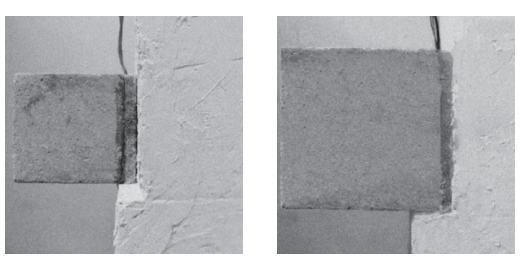

(b) (c)

Figure 4: Test models: (a) schematic; (b) small specimen; (c) large specimen.

concentrated from June to September, and the precipitation reaches $456 \mathrm{~mm}$. The natural mountain in which the hazardous rock mass is located is steep, with a slope inclination of $65^{\circ}-80^{\circ}$. Sparse vegetation exists on the slope, and the root system develops along the joints and fissures. The hazardous rock mass is weathered metamorphic rock, with low mechanical strength, water permeability, and weathering resistance. The size of the hazardous rock mass is approximately $3.1 \times 3.3 \times 3.4 \mathrm{~m}$. Clear joints and gravitational unloading cracks have developed; the back and lower 
TABLE 1: Size and weight of the materials.

\begin{tabular}{lccccc}
\hline \multirow{2}{*}{ Material parameters } & \multicolumn{2}{c}{ Small specimen } & \multicolumn{2}{c}{ Large specimen } \\
& & Unstable block & Weak structural plane & Unstable block & Weak structural plane \\
\hline \multirow{3}{*}{ Size $(\mathrm{cm})$} & 7.1 & 7.1 & 14.0 & 14.0 \\
& Length & 7.1 & 0.6 & 14.0 & 1.1 \\
\hline Mass $(\mathrm{g})$ & Height & 7.1 & 7.1 & 14.0 & 14.0 \\
\hline
\end{tabular}

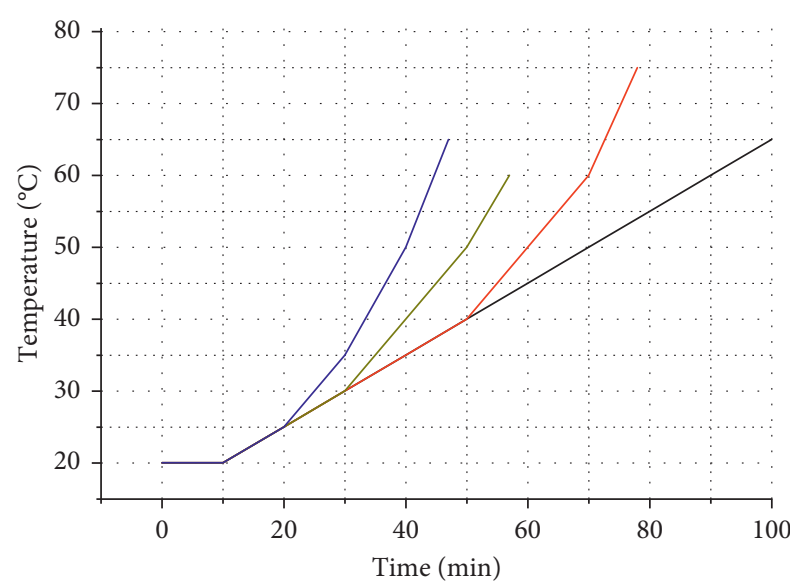

_ Test 1 (small specimen) _ _ Test 3 (large specimen) — Test 2 (small specimen) _ _ Test 4 (large specimen)

Figure 5: Temperature gradient heating modes.

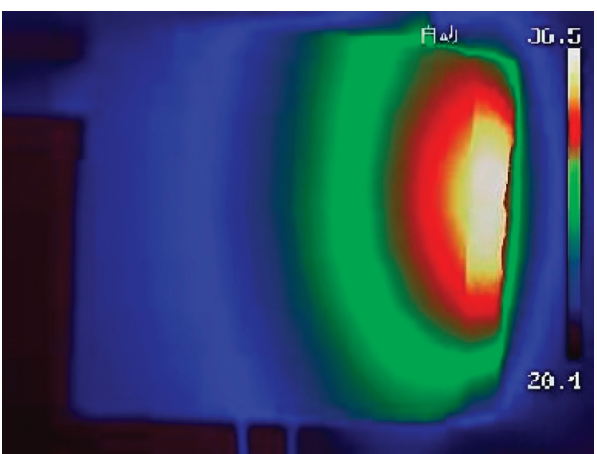

Figure 6: Infrared thermal image of the concrete block.

parts exhibit a vertical weak-fracture zone and local compression-crushed phenomenon, respectively. Figure 11 shows a schematic of the hazardous rock and sensor locations on-site.

4.2. Monitoring Results. Using the proposed monitoring system, the rock tilt, sensor temperature, and rainfall were automatically monitored. The initial frequency of data transmission was once an hour, and the tilt angle was the average value of 1000 collected data points in $1 \mathrm{~s}$. At 10:00 am on May 3, 2020 (UTC + 8), the monitoring system was deployed. The 3 sensors were tightly fixed on the slope, and initial data were obtained. Figure 12 shows the tilt angle and temperature curve of the MEMS tiltmeter 3 in the preceding week. In general, although temperature compensation is conducted in the production of the equipment, due to the influence of the ambient temperature, sensitive structures such as chips and circuit boards produce deformation and stress changes, resulting in the temperature drift of the tilt angle. Through the fitting analysis of the actual monitoring data, the piecewise linear relationship between the tilt angle and temperature can be obtained:

$$
\theta= \begin{cases}-0.00848 T+0.20101, & 10 \leq T<20, \\ 0.00706 T-0.09795, & 20 \leq T \leq 30, \\ -0.00199 T-0.15064, & 30<T \leq 40,\end{cases}
$$

where $\theta$ and $T$ represent the tilt angle and temperature collected by the MEMS tiltmeter, respectively.

Consequently, the second temperature compensation of the monitoring data of the three sensors was conducted to obtain more accurate data by using the fitting relationship equation and considering the sensor temperature of $20^{\circ} \mathrm{C}$ (normal temperature) as the reference.

At 16:00 pm on July 18, $2020(\mathrm{UTC}+8)$, due to the external effects of rain erosion, the tilt angle change exceeded $1.5^{\circ}$, as monitored by the sensor installed on the hazardous rock. The tilt angle rate increased rapidly, and finally, the hazardous rock collapsed at 2:26 am on July 19, 2020 $(\mathrm{UTC}+8)$. Figure 13 shows the image after the collapse of the hazardous rock.

Figure 14 shows the time history curve of the evolution trend of the tilt angles obtained using tiltmeters $1-3$. The data monitored using tiltmeter 1 and tiltmeter 2 were stable. Due to environmental factors, the data inevitably fluctuated, but the inclination angle changed within $0.3^{\circ}$. The data obtained using tiltmeter 3 exhibited notable stage characteristics. On June 10, 2020, the tilt angle gradually increased to approximately $0.8^{\circ}$ and later stabilized; the growth rate rapidly increased in the $81 \mathrm{~h}$ before the collapse of the hazardous rock. Only $26 \mathrm{~min}$ was required for the tilt angle to change from $1.95^{\circ}$ to $25.90^{\circ}$ (failure angle). Figure 15 shows the time history curve of the tilt angle monitored using tiltmeter 3 and the hourly rainfall in the monitoring area. The maximum hourly rainfall occurred at 13:00 on May 9, $2020(\mathrm{UTC}+8)$, but the tilt angle did not produce a notable response. To understand the correlation between the inclination angle and rainfall and avoid the influence of measurement errors, noise, and time lags between the causes and reactions of hazardous rock, a three-day unit was considered to plot the relationship between the tilt angle rate and precipitation, as 


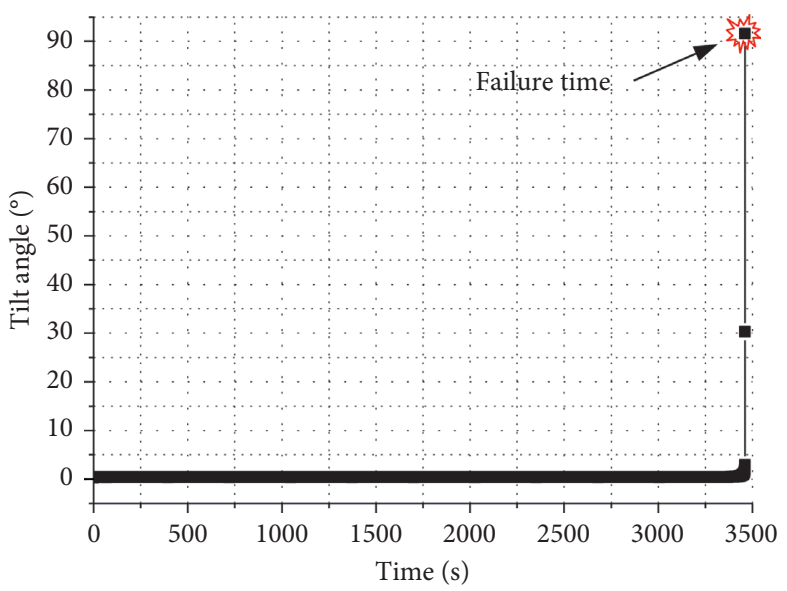

- - Tilt angle trend

(a)

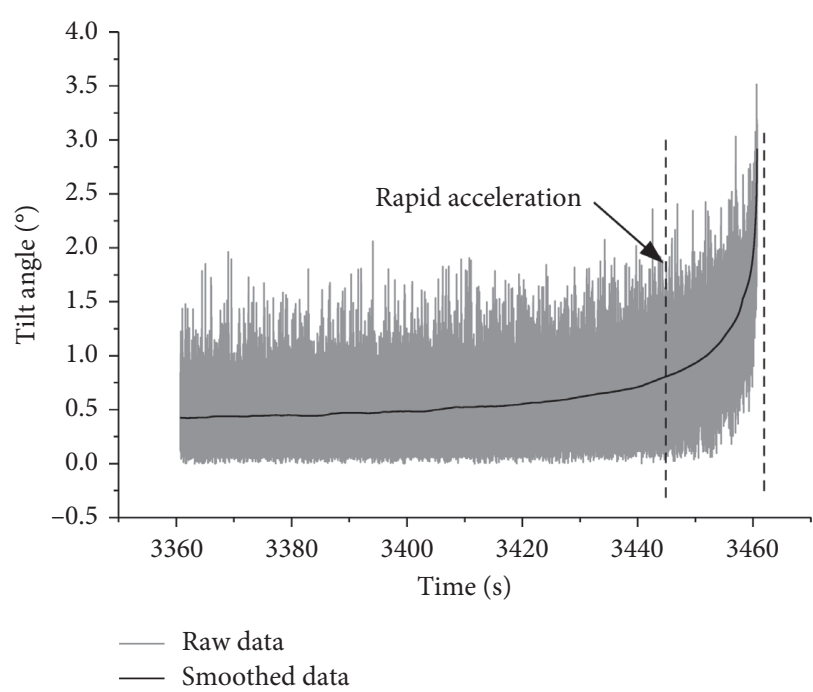

(b)

Figure 7: Time history of the tilt angle in test 1: (a) whole time history; (b) acceleration stage.

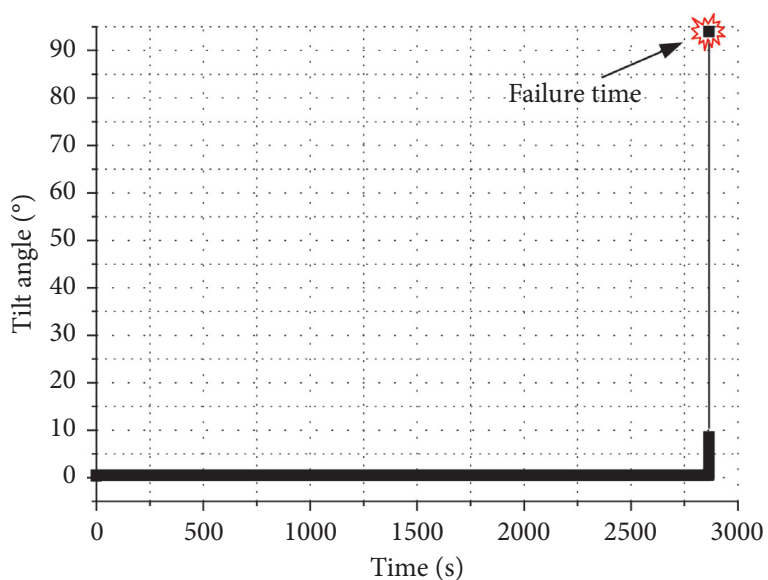

- - Tilt angle trend

(a)

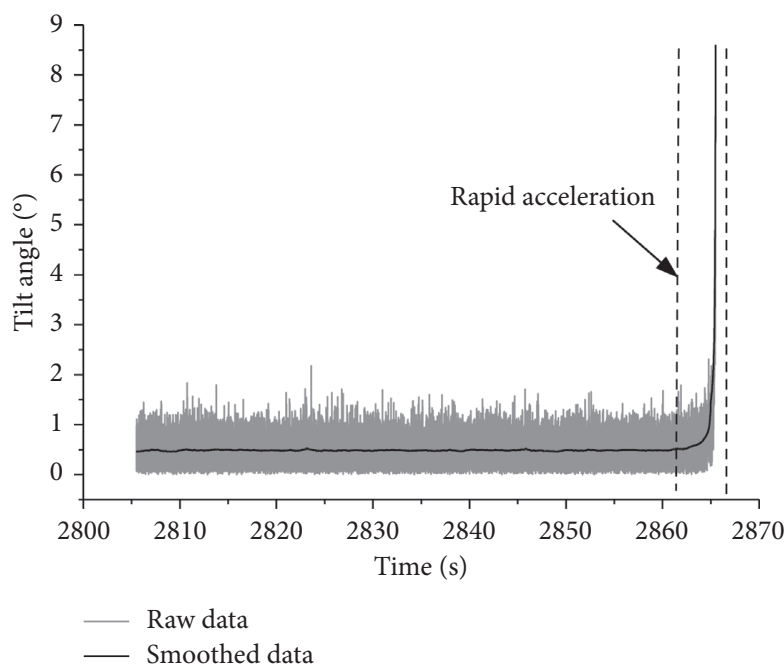

(b)

Figure 8: Time history of the tilt angle in test 2: (a) whole time history; (b) acceleration stage.

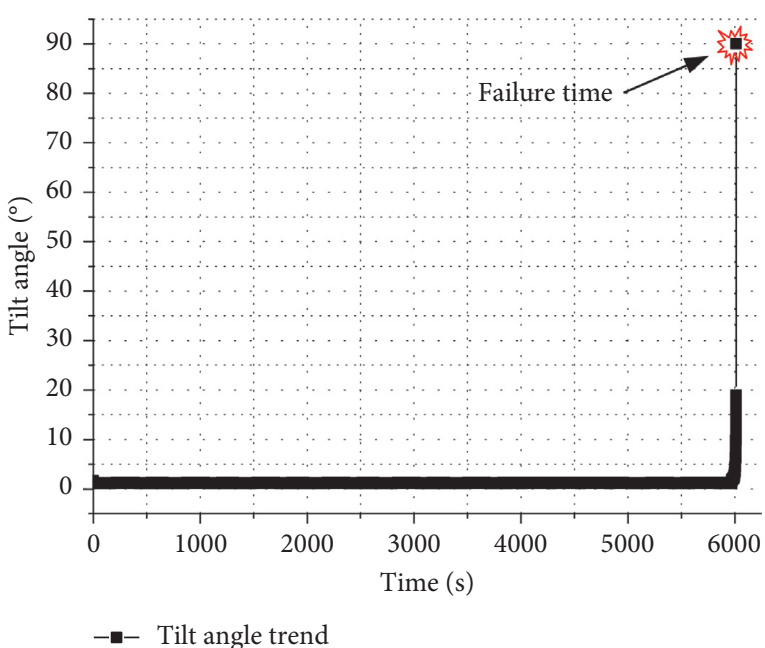

(a)

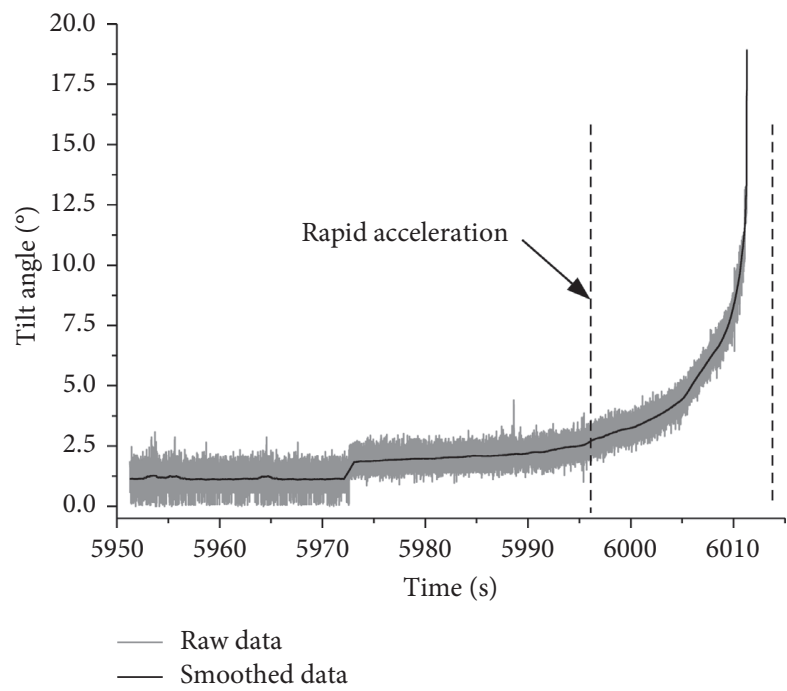

(b)

Figure 9: Time history of the tilt angle in test 3: (a) whole time history; (b) acceleration sage. 


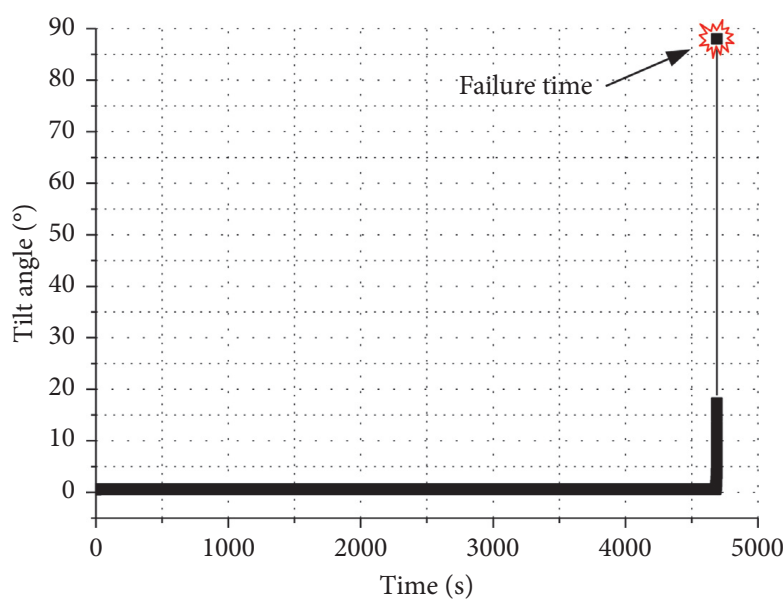

- - Tilt angle trend

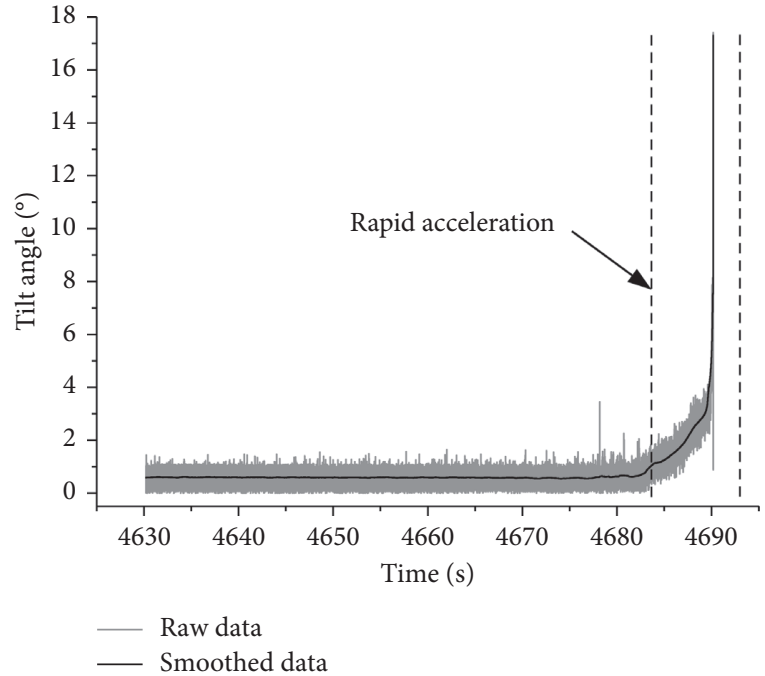

(b)

Figure 10: Time history of the tilt angle in test 4: (a) whole time history; (b) acceleration stage.

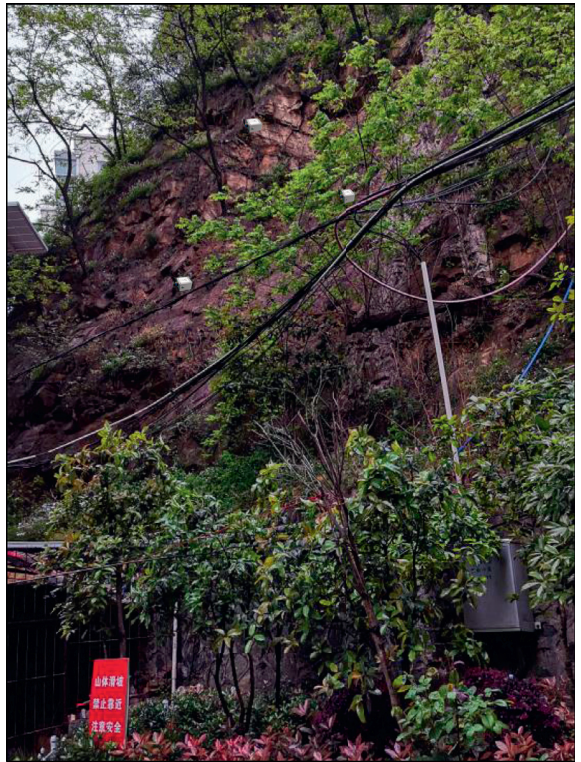

(a)

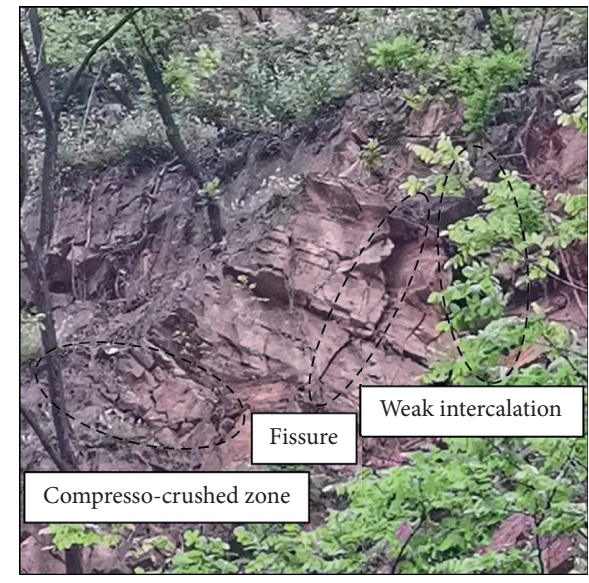

(b)

Figure 11: Continued. 


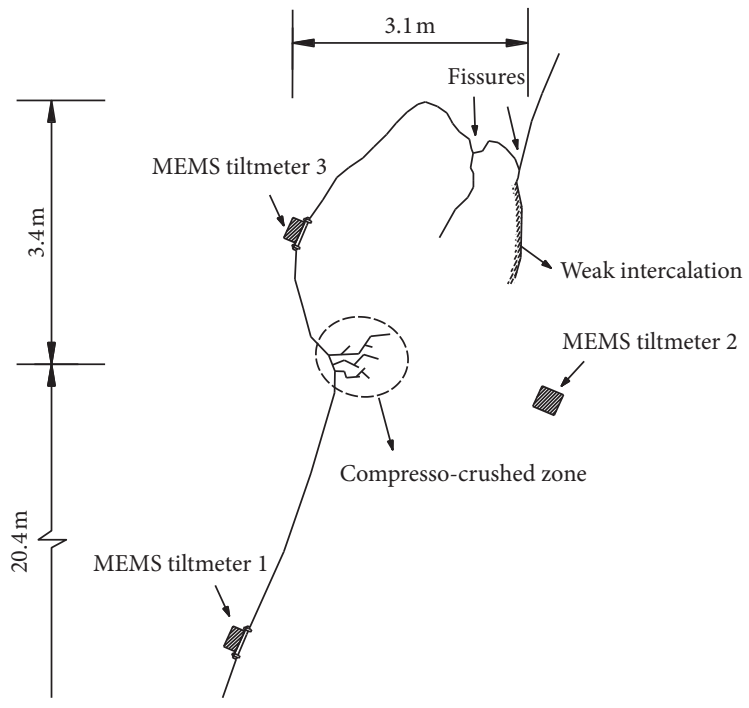

(c)

FIGURE 11: Image of the hazardous rock mass on-site: (a) slope; (b) hazardous rock; (c) cross-sectional sketch.

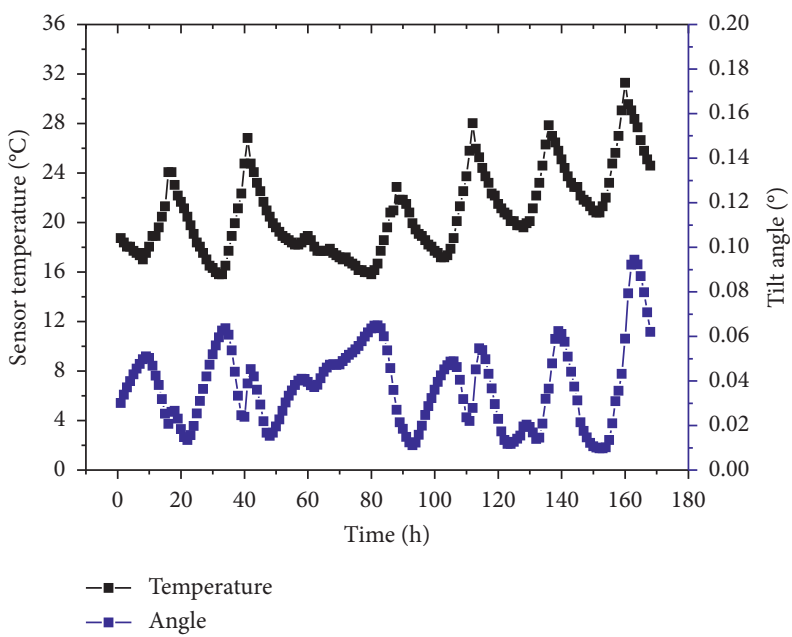

FIGURE 12: Tilt angle and temperature of tiltmeter 3 in the preceding week.

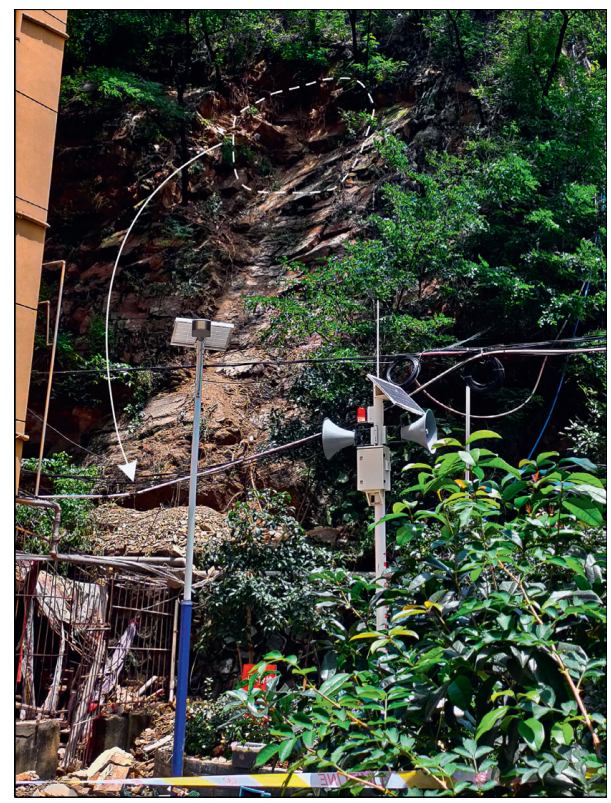

FIGURE 13: Image after the collapse of the hazardous rock. 


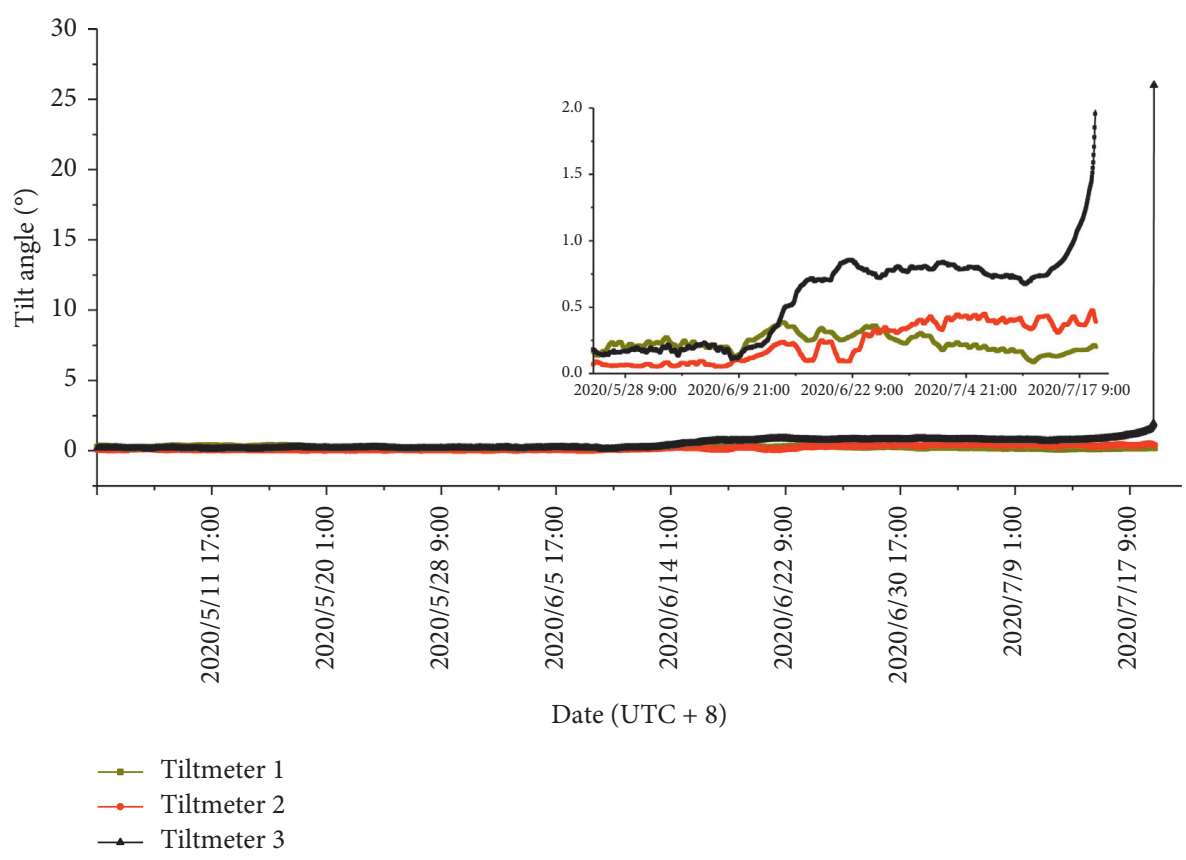

FIgURE 14: Tilt angle of tiltmeters 1-3.

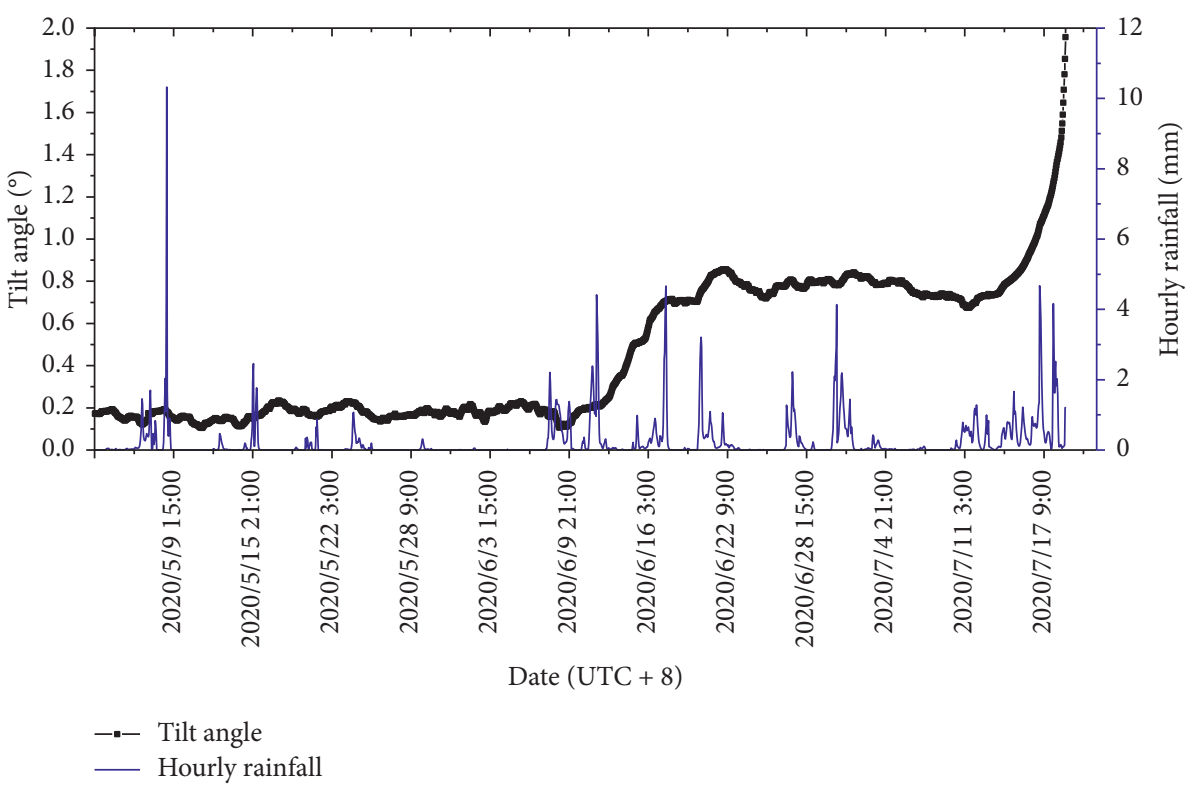

FIGURE 15: Hourly rainfall and tilt angle of the hazardous rock.

shown in Figure 16. The tilt rate and precipitation were weakly correlated, indicating that rainfall did not directly influence the deformation of the hazardous rock. Figure 17 shows the time history of precipitation during the study period. The precipitation for 3 and 5 days before collapse is the maximum during the monitoring period, which is about 3.5 times of the mean precipitation, indicating that rainfall is an important inducing factor for the collapse.
4.3. Failure Prediction Model. The results of the model test and field monitoring demonstrate that hazardous rock exhibits the failure precursor behavior of a rapidly accelerated increase in the tilt rate. Figure 18 shows the relation between the reciprocal tilt rate and time of the rapid acceleration process, as obtained from the model test. An approximately linear relation exists between the reciprocal tilt rate and time, and the fitting equations can be derived. The relevant expressions are as follows: 


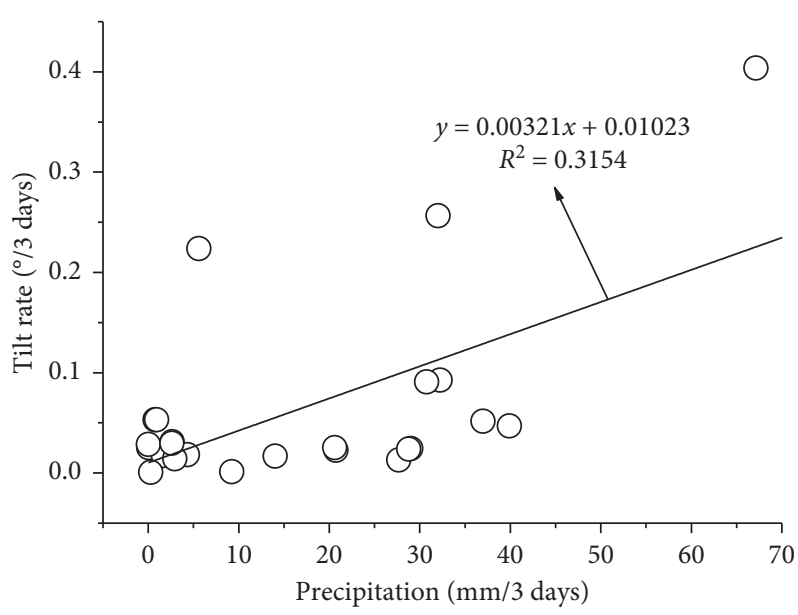

Figure 16: Correlation between the precipitation and tilt rate.

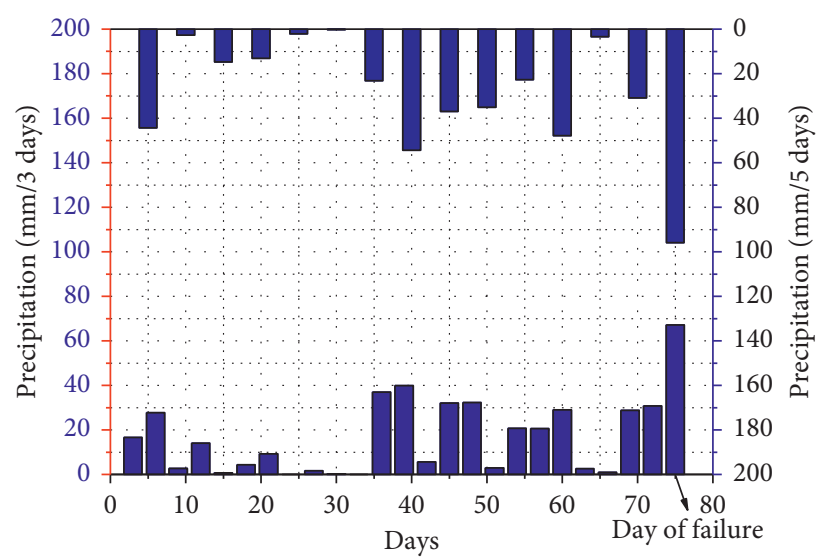

FIgURE 17: Time history of precipitation during the study period.

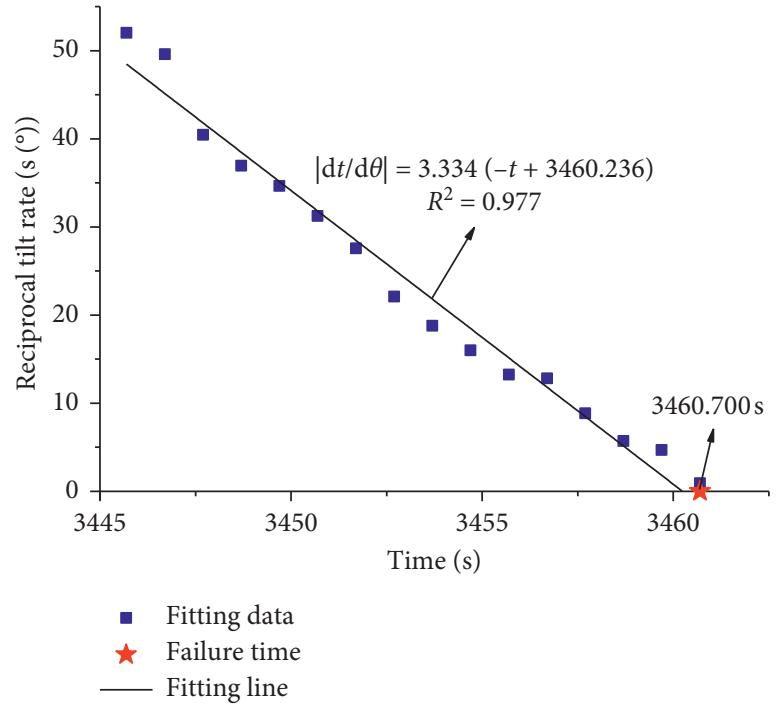

(a)

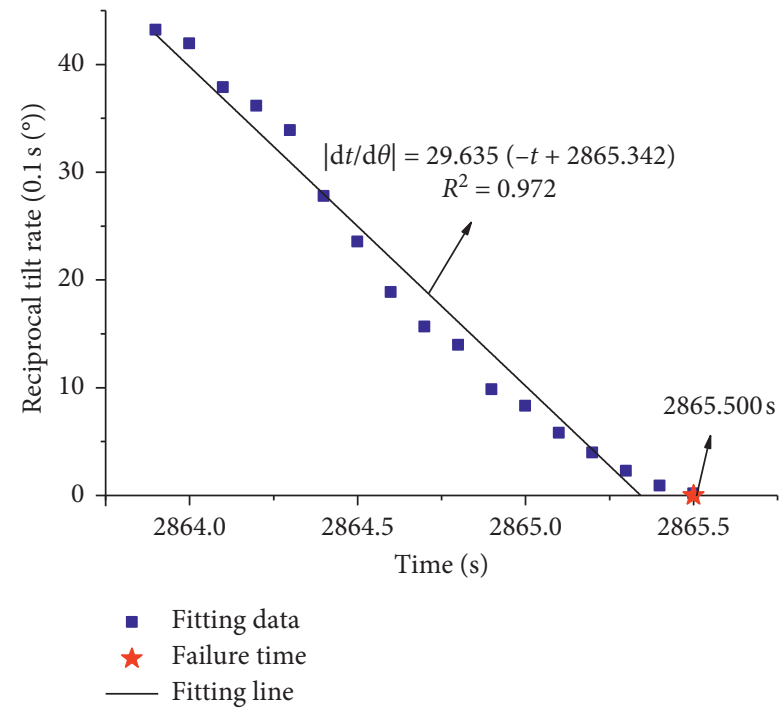

(b)

Figure 18: Continued. 


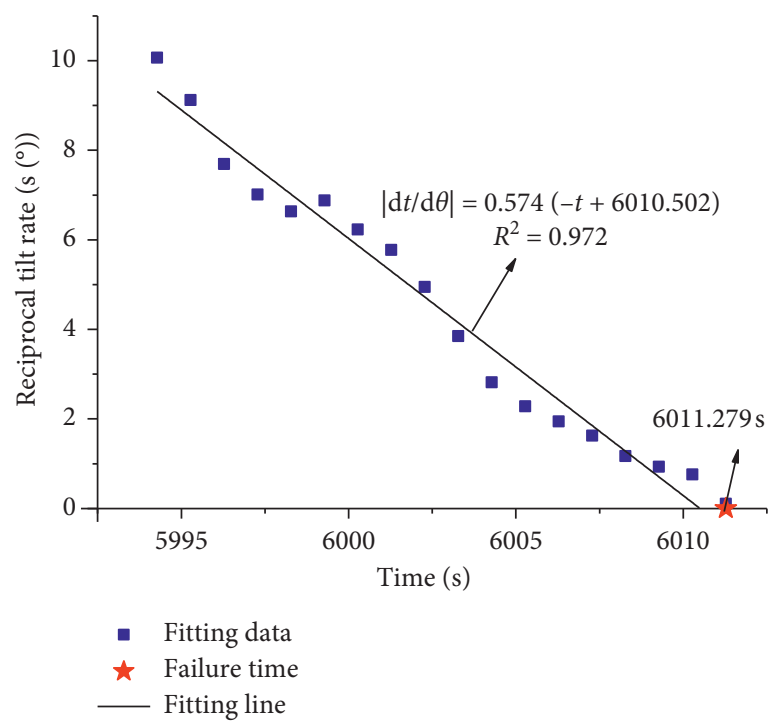

(c)

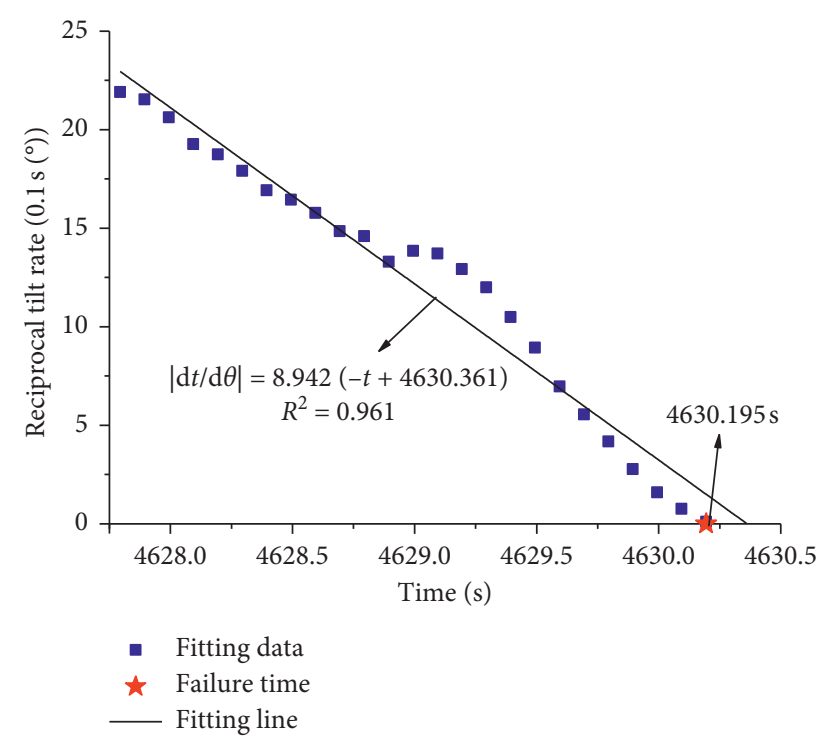

(d)

FIgURE 18: Relation between the reciprocal tilt rate and time in the model test: (a) test 1; (b) test 2; (c) test 3; (d) test 4.

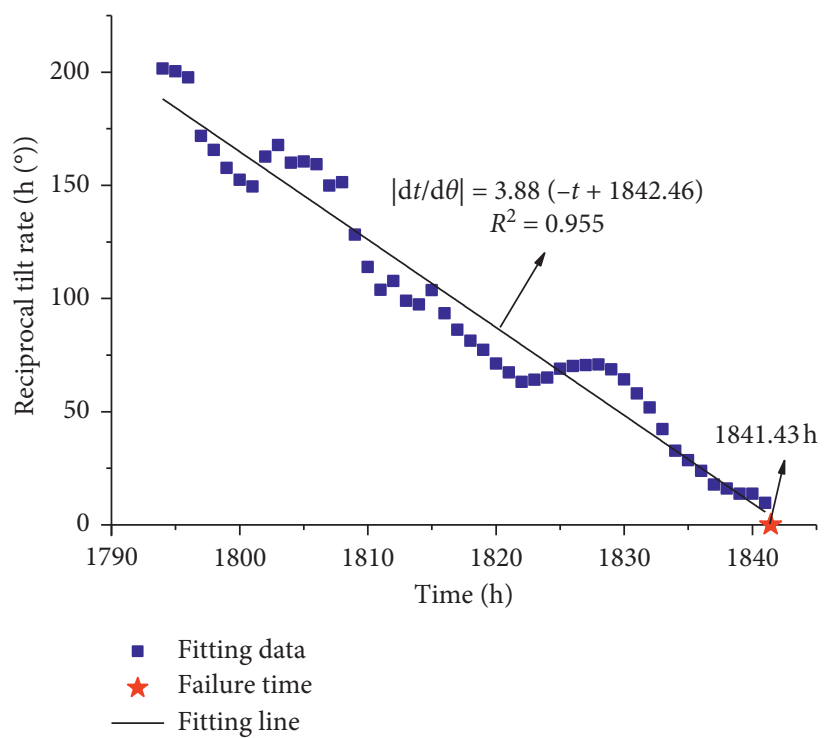

FIGURE 19: Relation between the reciprocal tilt rate and time of field monitoring.

$$
\left|\frac{\mathrm{d} t}{\mathrm{~d} \theta}\right|=a\left(t_{f}-t\right)
$$

where $\mathrm{d} t / \mathrm{d} \theta$ is the reciprocal tilt rate, $t$ is the time, and $a$ and $t_{f}$ are the fitting parameters.

The calculation method of the reciprocal slope rate is

$$
\left|\frac{\mathrm{d} t}{\mathrm{~d} \theta}\right|_{t=t_{n}}=\left|\frac{t_{n}-t_{n-1}}{\theta_{n}-\theta_{n-1}}\right|,
$$

where $t_{n}$ and $t_{n-1}$ denote the $n^{\text {th }}$ and $(n-1)^{\text {th }}$ sampling time, respectively; $\theta_{n}\left({ }^{\circ}\right)$ and $\theta_{n-1}\left({ }^{\circ}\right)$ denote the tilt angle at $t_{n}$ and $t_{n-1}$, respectively.
The form of equation (6) is the same as that of equation (1) with $\alpha=2$. Furthermore, it is assumed that the tilt angle rate at the moment of failure is infinite, i.e., $\mathrm{d} t / \mathrm{d} \theta=0$. According to equation (6), the predicted failure time is $t_{f}$. According to Figure 17, in the four sets of tests, the failure time obtained from the linear fitting line is similar to the actual failure time.

For on-site monitoring, the data $50 \mathrm{~h}$ before failure are selected for fitting, and the results are shown in Figure 19. The reciprocal tilt rate exhibits a linear relationship with time in the rapid acceleration process. The failure time predicted using the fitting curve is $3: 28$ am on July 19, 2020 $(\mathrm{UTC}+8)$, which is close to the actual failure time at 2:26 am 
TABLe 2: Comparison of the predicted failure time and actual failure time in the model test.

\begin{tabular}{|c|c|c|c|c|}
\hline \multicolumn{2}{|c|}{ Category } & Predicted failure time $\left(T_{\mathrm{pf}}\right)(\mathrm{s})$ & Actual failure time $\left(T_{\mathrm{af}}\right)(\mathrm{s})$ & $T_{\mathrm{pf}}-T_{\mathrm{af}}(\mathrm{s})$ \\
\hline \multirow{4}{*}{ Model test } & Test 1 & 3460.236 & 3460.700 & -0.464 \\
\hline & Test 2 & 2865.342 & 2865.500 & -0.068 \\
\hline & Test 3 & 6010.502 & 6011.279 & -0.777 \\
\hline & Test 4 & 4630.361 & 4630.195 & 0.171 \\
\hline
\end{tabular}

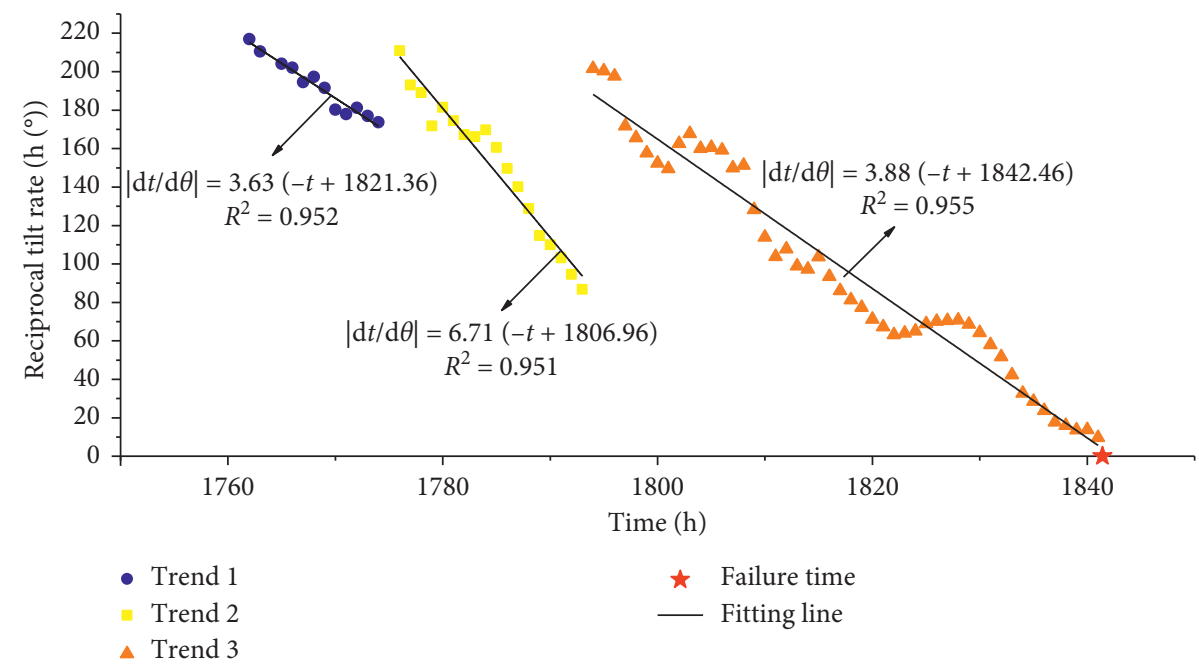

FIgURE 20: Time history of the reciprocal tilt angle rate in the whole acceleration stage.

TABLE 3: Comparison of the predicted failure time and actual failure time in field monitoring.

\begin{tabular}{ccccc}
\hline Category & & Predicted failure time $\left(T_{\mathrm{pf}}\right)(\mathrm{h})$ & Actual failure time $\left(T_{\mathrm{af}}\right)(\mathrm{h})$ & $T_{\mathrm{pf}}-T_{\mathrm{af}}(\mathrm{h})$ \\
\hline \multirow{3}{*}{ Field monitoring } & Trend 1 & 1821.360 & 1841.430 & $-20.07 \mathrm{~h}$ \\
& Trend 2 & 1806.960 & & $-34.47 \mathrm{~h}$ \\
& Trend 3 & 1842.460 & $-1.03 \mathrm{~h}$ \\
\hline
\end{tabular}

on July 19, $2020(\mathrm{UTC}+8)$. This result shows that the proposed method can guide the accurate and effective risk management of hazardous rock failure.

\section{Discussion}

In this study, physical model tests were conducted to obtain the tilt angle history data of the process of block instability caused by the deterioration of the main control structural plane. Since the structural plane in the test was a homogeneous material, a linear relation existed between the reciprocal tilt angle rate and time in the acceleration stage. Assuming the tilt angle rate to be infinite, the time of block instability could be accurately predicted using equation (6), with an error of less than $1 \mathrm{~s}$. The specific fitting results are given in Table 2 . The proposed method was verified through field monitoring, and the data $50 \mathrm{~h}$ before the instability were in agreement with those obtained using the proposed prediction model.

Furthermore, we fitted the data of the complete acceleration stage in the field monitoring. The time history of the reciprocal tilt angle rate is shown in Figure 20. Three linear trends can be observed between the reciprocal tilt angle rate and time due to the nonlinear expansion of the rock mass fractures in the field. The detailed calculation results of the prediction model are given in Table 3 . The prediction results of the first two trends exhibit large errors, and the last linear trend before failure exhibits a more accurate prediction result with an error of $1.03 \mathrm{~h}$. Therefore, in the process of early warning judgment, attention should be focused on the change in the acceleration trend in the process of deformation monitoring [20]. When the trend of the reciprocal tilt angle rate changes, a new linear fitting should be conducted to obtain accurate prediction results.

In addition, we selected different data volumes for the last linear trend of the reciprocal tilt angle rate as samples to analyze the fitting errors under different forecast lead times. The detailed fitting results are shown in Figure 21. The prediction model provided a reasonably accurate prediction $12 \mathrm{~h}$ before the failure of the hazardous rock masses, and the error was approximately $1 \mathrm{~h}$. Therefore, the prediction method exhibited a high timeliness. Moreover, because onsite monitoring was affected by the ambient temperature, the reciprocal tilt angle rate for the same linear acceleration trend process exhibited certain fluctuations. Figure 22 shows the frequency spectrum of the data monitored using 


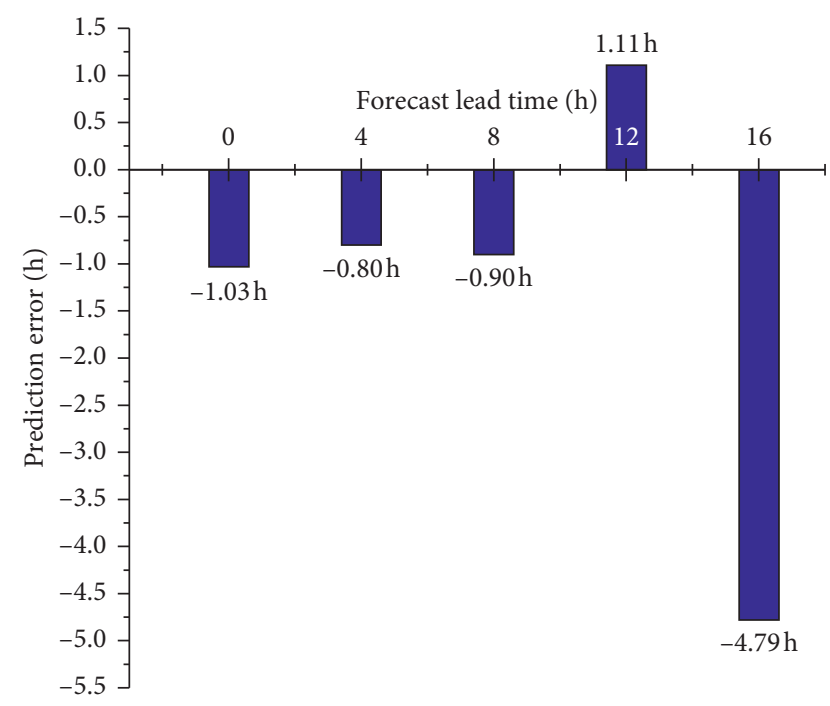

Figure 21: Fitting error pertaining to different forecast lead times.

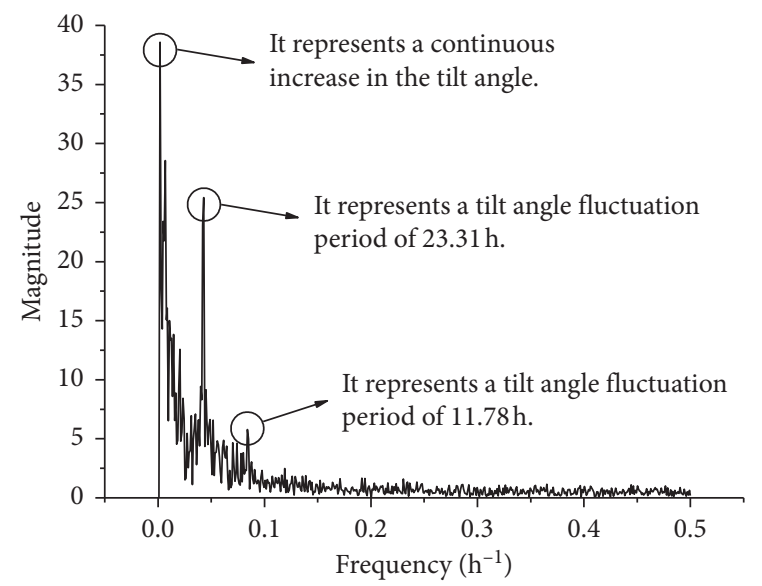

FIGURE 22: Frequency domain curves pertaining to the tilt angle data obtained using tiltmeter 3 .

tiltmeter 3; a total of 1,807 data points were recorded in the monitoring. Due to the change in the ambient temperature caused by the alternation of day and night, the variation in the tilt angle corresponded to cyclic fluctuations. According to the spectrogram, the fluctuation periods were approximately $1 \mathrm{~d}$. Therefore, to more accurately predict the failure time of hazardous rock, the duration of the acceleration stage must be at least $24 \mathrm{~h}$.

\section{Conclusions}

(1) Combining a MEMS acceleration sensor with the calculation principle of the space vector including angle, a tilt angle monitoring algorithm is established, and a hazardous rock automatic monitoring system is developed by integrating acquisition and transmission capabilities and a power supply.
(2) A physical model test is designed, in which a thermally sensitive material (with heat-sensitive strength) is used as the weak structural plane of the hazardous block, and the evolution characteristic of the tilt angle before failure of the block during the process of structural plane deterioration is obtained. The accelerated evolution of the tilt angle is a precursor to hazardous rock failure. In the process of rapid acceleration, an approximately linear relationship exists between the reciprocal tilt angle rate and time, and the relevant equations are derived. Assuming the tilt angle rate to be infinite, the failure time of hazardous blocks can be predicted using the correlation equation.

(3) An automatic tilt angle monitoring system is deployed for hazardous rock in Hubei Province, China. The inclination evolution trend of the whole process of rock failure is obtained, and the feasibility of the monitoring method and prediction model is verified. However, in the process of early warning judgment, attention should be focused to the change in the acceleration trend in the process of deformation monitoring. When the trend of the reciprocal tilt angle rate changes, a new linear fitting should be conducted to obtain accurate prediction results.

\section{Data Availability}

The data used to support the findings of this study are included within the article.

\section{Conflicts of Interest}

The authors declare that they have no conflicts of interest.

\section{Acknowledgments}

The authors gratefully acknowledge the financial support from the Beijing Science and Technology Project of China (Z201100005820008) and Science and Technology Plan Project of Yunnan Provincial Department of Transportation of China (Yunjiao Science and Education (2018-35)).

\section{References}

[1] H. K. Chen, H. M. Tang, and S. Q. Ye, "Damage model of control fissure in perilous rock," Applied Mathematics and Mechanics, vol. 27, no. 7, pp. 967-974, 2006.

[2] E. Hoek and J. W. Bray, Rock Slope Engineering, The Institution of Mining and Metallurgy, London, UK, 1977.

[3] G. Zhang, F. Wang, H. Zhang, H. Tang, and X. H. Li, "New stability calculation method for rock slopes subject to flexural toppling failure," International Journal of Rock Mechanics and Mining Sciences, vol. 106, pp. 319-328, 2018.

[4] C. Shi, B. Yang, Y. P. Zhang, and J. X. Yang, "Application of discrete-element numerical simulation for calculating the stability of dangerous rock mass: a case study," International Journal of Rock Mechanics and Mining Sciences, vol. 20, no. 12, pp. 1-11, 2020.

[5] Z. He, M. W. Xie, Z. J. Huang et al., "Experimental hazardous rock block stability assessment based on vibration feature 
parameters," Advances in Civil Engineering, vol. 2020, Article ID 8837459, 11 pages, 2020.

[6] P. Lin, X. Liu, W. Zhou, R. Wang, and S. Wang, "Cracking, stability and slope reinforcement analysis relating to the Jinping dam based on a geomechanical model test," Arabian Journal of Geosciences, vol. 8, no. 7, pp. 4393-4410, 2015.

[7] Z. Tao, Y. Wang, C. Zhu, H. Xu, G. Li, and M. He, "Mechanical evolution of constant resistance and large deformation anchor cables and their application in landslide monitoring," Bulletin of Engineering Geology and the Environment, vol. 78, no. 7, pp. 4787-4803, 2019.

[8] C. Atzeni, M. Barla, M. Pieraccini, and F. Antolini, "Early warning monitoring of natural and engineered slopes with ground-based synthetic-aperture radar," Rock Mechanics and Rock Engineering, vol. 48, no. 1, pp. 235-246, 2015.

[9] R. A. Kromer, D. J. Hutchinson, M. J. Lato, D. Gauthier, and T. Edwards, "Identifying rock slope failure precursors using lidar for transportation corridor hazard management," Engineering Geology, vol. 195, pp. 93-103, 2015.

[10] H. B. Li, X. G. Yang, H. L. Sun, S. C. Qi, and J. W. Zhou, "Monitoring of displacement evolution during the pre-failure stage of a rock block using ground-based radar interferometry," Landslides, vol. 16, no. 3, pp. 1721-1730, 2019.

[11] T. Carlà, T. Nolesini, L. Solari, C. Rivolta, L. Dei Cas, and N. Casagli, "Rockfall forecasting and risk management along a major transportation corridor in the Alps through groundbased radar interferometry," Landslides, vol. 16, no. 8, pp. 1425-1435, 2019.

[12] T. Uchimura, I. Towhata, L. Wang et al., "Precaution and early warning of surface failure of slopes using tilt sensors," Soils and Foundations, vol. 55, no. 5, pp. 1086-1099, 2015.

[13] T. Uchimura, I. Towhata, T. T. Lan Anh et al., "Simple monitoring method for precaution of landslides watching tilting and water contents on slopes surface," Landslides, vol. 7, no. 3, pp. 351-357, 2010.

[14] J. A. Smethurst, A. Smith, S. Uhlemann et al., "Current and future role of instrumentation and monitoring in the performance of transport infrastructure slopes," Quarterly Journal of Engineering Geology and Hydrogeology, vol. 50, no. 3, 2015.

[15] D. Abhirup, S. D. Neelima, and T. Ikuo, "Early warning system using tilt sensors in Chibo, Kalimpong, Darjeeling Himalayas, India," Natural Hazards, vol. 94, pp. 727-741, 2018.

[16] J. R. Xie, T. Uchimura, G. H. Wang et al., "Predicting the sliding behavior of rotational landslides based on the tilting measurement of the slope surface," Engineering Geology, vol. 269, 2020.

[17] M. W. Xie, Z. He, L. Liang, Z. X. Wu, and G. C. Sun, "Slope disaster monitoring and early warning system based on 3DMEMS and NB-IoT," in Proceedings of the IEEE 4th Advanced Information Technology, Electronic and Automation Control Conference (IAEAC), pp. 90-94, Chengdu, China, December 2019.

[18] M. Saito, "Forecasting the time of occurrence of a slope failure," in Proceedings of the 6th International Conference on Soil Mechanics and Foundation Engineering, vol. 2, pp. 537541, Pergamon Press, Montreal, Canada, September 1965.

[19] T. Fukuzono, "A method to predict the time of slope failure caused by rainfall using the inverse number of velocity of surface displacement," Landslides, vol. 22, no. 2, pp. 8-13, 1985.

[20] T. Fukuzono, "A new method for predicting the failure time of a slope," in Proceedings of the 4th International Conference and Field Workshop on Landslides, pp. 145-150, Tokyo, Japan, Augest 1985.

[21] T. Fukuzono, "A simple method for predicting the failure time of slope-using reciprocal of velocity," Technology for Disaster Prevention, Science and Technology Agency, vol. 1, no. 13, pp. 111-128, 1989.

[22] A. Federico, M. Popescu, G. Elia, C. Fidelibus, G. Internò, and A. Murianni, "Prediction of time to slope failure: a general framework," Environmental Earth Sciences, vol. 66, no. 1, pp. 245-256, 2012.

[23] F. Bozzano, I. Cipriani, P. Mazzanti, and A. Prestininzi, "A field experiment for calibrating landslide time-of-failure prediction functions," International Journal of Rock Mechanics and Mining Sciences, vol. 67, pp. 69-77, 2014.

[24] L. Xue, S. Q. Qin, P. Li, G. L. Li, I. A. Oyediran, and X. H. Pan, "New quantitative displacement criteria for slope deformation process: from the onset of the accelerating creep to brittle rupture and final failure," Engineering Geology, vol. 182, pp. 79-87, 2014.

[25] A. Manconi and D. Giordan, "Landslide early warning based on failure forecast models: the example of the Mt. de La Saxe rockslide, Northern Italy," Natural Hazards and Earth System Sciences, vol. 15, no. 7, pp. 1639-1644, 2015.

[26] T. Carlà, E. Intrieri, F. D. Traglia, T. Nolesini, G. Gigli, and N. Casagli, "Guidelines on the use of inverse velocity method as a tool for setting alarm thresholds and forecasting landslides and structure collapses," Landslides, vol. 14, no. 2, pp. 517-534, 2017.

[27] J. Zhang, Z. P. Wang, G. D. Zhang, and Y. D. Xue, "Probabilistic prediction of slope failure time," Engineering Geology, vol. 1271, 2020.

[28] X. P. Zhou, L. J. Liu, and C. Xu, "A modified inverse-velocity method for predicting the failure time of landslides," Engineering Geology, vol. 268, 2020.

[29] B. Voight, "A method for prediction of volcanic eruptions," Nature, vol. 332, no. 6160, pp. 125-130, 1988.

[30] B. Voight, "A relation to describe rate-dependent material failure," Science, vol. 243, no. 4888, pp. 200-203, 1989.

[31] C. R. J. Kilburn and D. N. Petley, "Forecasting giant, catastrophic slope collapse: lessons from Vajont, Northern Italy," Geomorphology, vol. 54, no. 1-2, pp. 21-32, 2003.

[32] N. D. Rose and O. Hungr, "Forecasting potential rock slope failure in open pit mines using the inverse-velocity method," International Journal of Rock Mechanics and Mining Sciences, vol. 44, no. 2, pp. 21-32, 2006.

[33] A. Mufundirwa, Y. Fujii, and J. Kodama, "A new practical method for prediction of geomechanical failure-time," International Journal of Rock Mechanics and Mining Sciences, vol. 47, no. 7, pp. 1079-1090, 2010.

[34] G. J. Dick, E. Eberhardt, A. G. CabrejoLiévano, D. Stead, and N. D. Rose, "Development of an early-warning time-of-failure analysis methodology for open-pit mine slopes utilizing ground-based slope stability radar monitoring data," Canadian Geotechnical Journal, vol. 52, no. 4, pp. 515-529, 2014.

[35] J. Xie, T. Uchimura, G. Wang et al., "A new prediction method for the occurrence of landslides based on the time history of tilting of the slope surface," Landslides, vol. 17, no. 2, pp. 301-312, 2020.

[36] Y. Y. Wang, X. Y. Fan, X. N. Gan, and J. G. Li, "Research and application of similarity theory for creep law under the action of temperature and pressure," Chinese Journal of Applied Mechanics, vol. 34, no. 6, pp. 1193-1199, 2017, in Chinese. 